\title{
Effects of vitamin D level on survival in patients with hepatocellular carcinoma
}

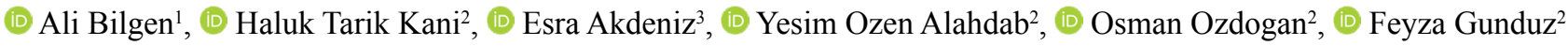 \\ ${ }^{1}$ Department of Internal Medicine, Marmara University School of Medicine, Istanbul, Turkey; ${ }^{2}$ Department of Internal Medicine and Gastroenterology, Marmara \\ University School of Medicine, Istanbul, Turkey; ${ }^{3}$ Department of Medical Education, Marmara University School of Medicine, Istanbul, Turkey
}

\begin{abstract}
Background and Aim: Hepatocellular carcinoma (HCC) is a life-threatening condition of the liver, often concurrent with vitamin D deficiency. In this study, we investigated the relationship between HCC patients' vitamin D levels and overall survival.

Materials and Methods: We retrospectively enrolled patients that were being followed on their HCC diagnosis. We collected and examined data on patients' $25-\mathrm{OH}$ vitamin $\mathrm{D}$ levels one month before diagnosis or at any point thereafter. We took levels below $10 \mathrm{ng} / \mathrm{mL}$ to indicate severe deficiency, levels between $10 \mathrm{ng} / \mathrm{mL}$ and $20 \mathrm{ng} / \mathrm{mL}$ to indicate moderate deficiency, and levels between $20 \mathrm{ng} / \mathrm{mL}$ and $30 \mathrm{ng} / \mathrm{mL}$ to indicate mild deficiency. We then analyzed the effects of vitamin D levels on patients' survival for each of these brackets.

Results: We included 85 patients in our survival analyses. We found $9 \mathrm{ng} /$ $\mathrm{mL}$ to be the significant cutoff vitamin D level for survival. Vitamin D levels were lower in cases of advanced disease. Univariate analysis showed that advanced Barcelona Clinic Liver Cancer (BCLC) grades, vitamin D levels below $9 \mathrm{ng} / \mathrm{mL}$, and alpha-fetoprotein (AFP) levels above $400 \mathrm{ng} / \mathrm{dL}$ had a negative significant effect on survival. Multivariate analysis showed that only advanced BCLC grades and AFP levels above $400 \mathrm{ng} / \mathrm{dL}$ had a negative significant effect.

Conclusion: In our study's cohort, HCC grades and AFP levels had a substantial negative impact on patients' overall survival. We found no connection, however, between vitamin D levels and overall survival.
\end{abstract}

Keywords: Hepatocellular carcinoma; survival; vitamin D.

\section{Introduction}

Liver cancer is a crucial health issue, as it is the fifth most common cancer and the second most frequent cause of cancer-related death worldwide. Hepatocellular carcinoma (HCC) can be found in near-

How to cite this article: Bilgen A, Kani HT, Akdeniz E, Ozen Alahdab Y, Ozdogan O, Gunduz F. Effects of vitamin D level on survival in patients with hepatocellular carcinoma. Hepatology Forum 2020; 1(3):97-100.

Received: July 02, 2020; Accepted: August 24, 2020; Available online: September 21, 2020

Corresponding author: Feyza Gunduz; Marmara Universitesi Tip Fakultesi, Gastroenteroloji Anabilim Dali, Istanbul, Turkey

Phone: +90 53346271 06; e-mail: drfgunduz@yahoo.com

(1) 9 OPEn Access

c. This work is licensed under a Creative Commons Attribution-NonCommercial 4.0 International License.

(C) Copyright 2020 by Hepatology Forum - Available online at www.hepatologyforum.org ly $90 \%$ of primary liver cancer cases. ${ }^{[1,2]}$ At the time of diagnosis, it is typically accompanied by cirrhosis, which tends to arise from excessive alcohol consumption or chronic viral hepatitis B or $\mathrm{C}^{[3]}$ Close medical surveillance following a cirrhosis diagnosis increases the probability of early $\mathrm{HCC}$ detection, and it therefore also increases overall survival. ${ }^{[4]}$

The main goal of HCC treatment is to increase patients' overall survival and quality of life. Besides early diagnosis, there are several factors influencing survival, including nutrition. Malnutrition is commonly related to cancer at large and HCC in particular, having a negative impact on survival and quality of life. ${ }^{[5]}$ Given that it is a potential cause of cirrhosis and HCC, it is important to identify it and correct patients' dietary deficiencies.

Vitamin D affects bone mineral metabolism and has an immunomodulatory effect, so its deficiency impacts the pathophysiology of malignancies and is commonly found in HCC patients, whose treatment and survival it may also negatively affect. ${ }^{[6]}$ The vitamin has further been found to inhibit the growth of HCC cell lines (especially HepG2 and Hep3B lines) in rats and humans. ${ }^{[7]}$ Moreover, it has been shown to increase cell fraction at the $G_{0} / G_{1}$ phase and decrease cell fraction at the $\mathrm{S}$ phase, and it is thought to cause cell cycle arrest at $\mathrm{G}_{0} / \mathrm{G}_{1} \cdot{ }^{[8]}$

Our aim is to investigate the relationship between vitamin $\mathrm{D}$ levels and overall survival in HCC patients.

\section{Materials and Methods}

\section{Participants}

We retrospectively enrolled the patients that were being followed up on their HCC diagnosis in our gastroenterology outpatient clinic between September 2010 and June 2016. HCC was diagnosed after establishing hypervascularity in the arterial phase and washout in the portal venous or delayed phases using dynamic contrast-enhanced computed tomography, magnetic resonance imaging, or histopathological examination of liver tissue from the primary lesion or the metastasis of the primary lesion. Following the European Association for the Study of the Liver (EASL) guidelines, the biopsy and histopathological examination were performed on all patients without an existing cirrhosis diagnosis. ${ }^{[3]}$

A treatment plan was crafted after a detailed examination of each patient by a multidisciplinary team, including a hepatobiliary surgeon, a nuclear medicine specialist, a radiologist, an oncologist, and a gastroenterologist. HCC patients considered early-stage per the Milan criteria were included in the national liver transplantation waiting list, and surgical resection or local ablative therapies were performed during the waiting period if needed. Radiofrequency ablation, trans-arterial 
chemoembolization (TACE), or a systemic treatment were performed on intermediate- and advanced-stage HCC patients. End-stage HCC patients received best supportive care with close monitoring. All patients were treated and monitored following the most current EASL guidelines available at the time. ${ }^{[3]}$

Our study's inclusion criteria were an HCC diagnosis established through a radiologic or histopathological examination, a minimum age of 18 , and a record of $25-\mathrm{OH}$ vitamin D levels measured one month before diagnosis or at any point thereafter. Exclusion criteria were the concurrence with HCC of primary malignancy and missing data on vitamin D levels.

All procedures performed in studies involving human participants were in accordance with the ethical standards of the institutional and/or national research committee and with the 1964 Helsinki declaration and its later amendments or comparable ethical standards. This study was approved by the Ethical Committee for Scientific Research of our university (Approval Date: 15 July 2016, Approval Number: 09.2016.418).

\section{Data Collection Procedure}

We took vitamin D levels below $10 \mathrm{ng} / \mathrm{mL}$ to indicate severe deficiency (SD), levels between $10 \mathrm{ng} / \mathrm{mL}$ and $20 \mathrm{ng} / \mathrm{mL}$ to indicate moderate deficiency (MoD), and levels between $20 \mathrm{ng} / \mathrm{mL}$ and 30 $\mathrm{ng} / \mathrm{mL}$ to indicate mild deficiency (MiD). In addition, we accepted levels above $30 \mathrm{ng} / \mathrm{mL}$ as normal. We analyzed and compared the effects of vitamin D levels among patients in these four groups. We collected data on patients' sociodemographic traits, vitamin D levels, etiologies of HCC, Barcelona Clinic Liver Cancer (BCLC) grades, treatments, follow-up duration, and survival, as well as data from hematological, histopathological, and radio-diagnostic studies. These data were drawn from hardcopy patient files and the hospital's electronic database. We took follow-up to end on the day in which the data were collected for surviving patients, and on the date of death for diseased patients.

\section{Vitamin D Measurement}

We measured 25-OH vitamin D concentrations using the electrochemiluminescence immunoassay method, using a Beckman Coulter 800 device and $25-\mathrm{OH}$ vitamin $\mathrm{D}$ kits.

\section{Statistical Analysis}

Descriptive statistics included frequencies, percentages, means, and standard deviations. We used a Kaplan-Meier and Cox regression for the survival analysis. We selected our variables using a forward likelihood ratio method in our Cox regression analysis. We used the KruskalWallis test to draw comparisons among more than two groups, accepting p-values below 0.05 as significant.

\section{Results}

Out of 265 patients initially considered for this study, we had to exclude 180 patients from this study due to missing vitamin D level measurements one month before the diagnosis or during the follow-up period (Fig. 1). The mean patient age was 60.45 years, and 66 patients $(77.6 \%)$ were male. The mean follow-up duration was $51.44 \pm 6.45$ months, and the mean survival after HCC diagnosis was $15.62 \pm 12.93$ months. 32 (37.7\%) patients died during the follow-up

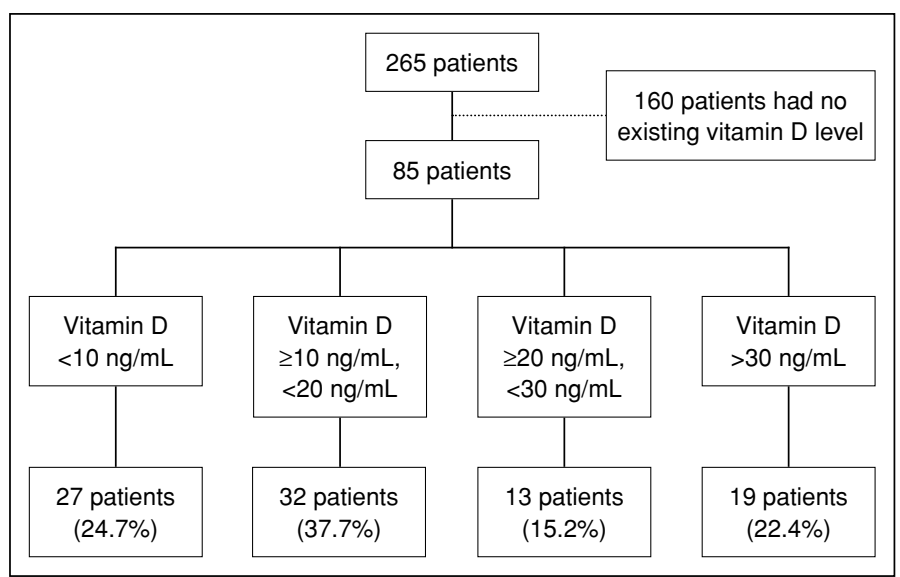

Figure 1. Flow chart of this study.

Table 1. Sociodemographic and clinical data of hepatocellular carcinoma patients

\begin{tabular}{|c|c|c|}
\hline & $\mathbf{n}$ & $\%$ \\
\hline Age (years) (Mean $\pm S D)$ & \multicolumn{2}{|c|}{$60.45 \pm 9.54$} \\
\hline Follow-up duration (months) (Mean \pm SD) & \multicolumn{2}{|c|}{$51.44 \pm 6.45$} \\
\hline \multicolumn{3}{|l|}{ Sex } \\
\hline Male & 66 & 77.6 \\
\hline Female & 19 & 22.4 \\
\hline \multicolumn{3}{|l|}{ Etiology of $\mathrm{HCC}$} \\
\hline Hepatitis B & 52 & 61.2 \\
\hline Hepatitis C & 10 & 11.7 \\
\hline Cryptogenic cirrhosis & 14 & 16.5 \\
\hline Alcoholic cirrhosis & 6 & 7.0 \\
\hline Other & 3 & 3.6 \\
\hline \multicolumn{3}{|l|}{ Cirrhosis status } \\
\hline Cirrhotic & 81 & 95.2 \\
\hline Non-cirrhotic & 2 & 2.4 \\
\hline \multicolumn{3}{|l|}{ Child classification } \\
\hline Child A & 49 & 57.6 \\
\hline Child B & 20 & 23.5 \\
\hline Child C & 6 & 7.1 \\
\hline \multicolumn{3}{|l|}{ Treatment } \\
\hline TACE & 29 & 34.1 \\
\hline RFA & 34 & 40.0 \\
\hline Surgical resection & 9 & 10.5 \\
\hline Liver transplantation & 11 & 12.9 \\
\hline Systemic chemotherapy & 11 & 12.9 \\
\hline Other & 18 & 20.9 \\
\hline \multicolumn{3}{|l|}{ Number of treatment } \\
\hline Single treatment & 52 & 61.1 \\
\hline Multiple treatments & 24 & 28.2 \\
\hline
\end{tabular}

SD: Standard deviation; HCC: Hepatocellular carcinoma; RFA: Radiofrequency ablation; TACE: Transarterial chemoembolization.

period. The mean vitamin D level was $17.5 \pm 11.29 \mathrm{ng} / \mathrm{mL}$ (Table 1). Twenty-one patients (24.7\%) had SD, 32 patients (37.7\%) had MoD, 


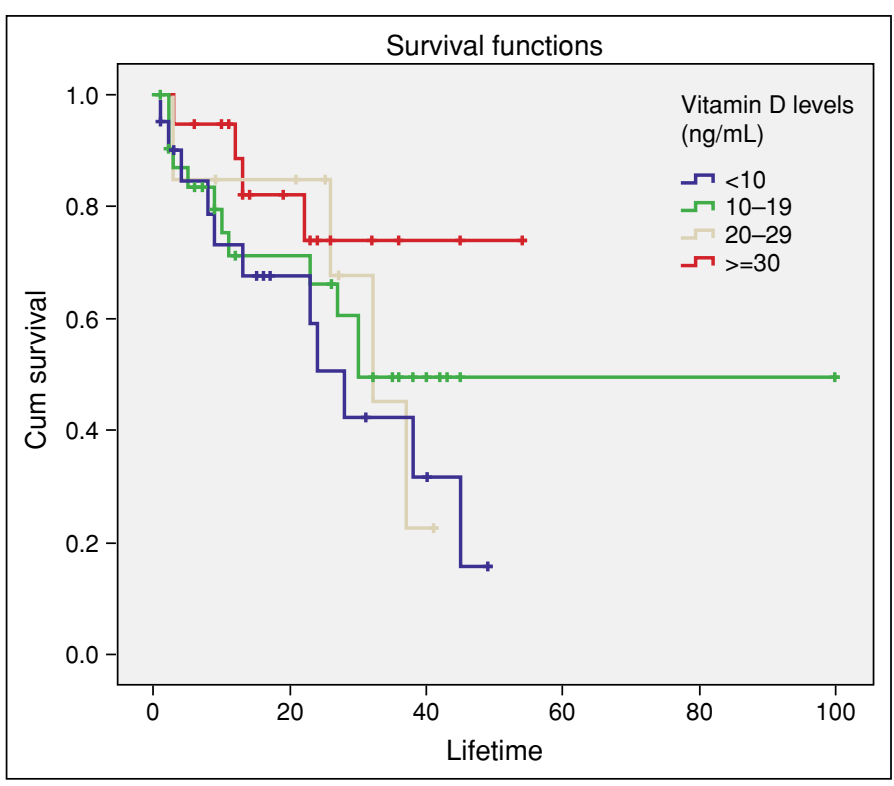

Figure 2. Vitamin D effects on HCC survival in four groups.

HCC: Hepatocellular carcinoma.

and 13 patients $(15.2 \%)$ had MiD. We found no difference in vitamin D levels' effect on survival among these four groups (Fig. 2). We found $9 \mathrm{ng} / \mathrm{mL}$ to be a significant cutoff vitamin $\mathrm{D}$ level for survival in our cohort $(\mathrm{p}=0.030)$.

When comparing vitamin D levels across Child-Pugh (CP) grades, we found that they were lower in advanced grades $(\mathrm{p}=0.035)$. In addition, we also found that they decreased in advanced BCLC grades $(\mathrm{p}=0.043)$.

Our univariate analysis showed that advanced BCLC grades, vitamin D levels below $9 \mathrm{ng} / \mathrm{mL}$, and alpha-fetoprotein (AFP) levels above $400 \mathrm{ng} / \mathrm{dL}$ had a negative significant effect on survival. Our multivariate analysis showed that only advanced BCLC grades and AFP levels above $400 \mathrm{ng} / \mathrm{dL}$ had a significant effect on survival (Table 2).

\section{Discussion}

We found vitamin D levels to be lower when HCC was concurrent with advanced cirrhosis or an advanced BCLC grade. However, we found no connection between survival and vitamin D levels. Only HCC grades and AFP levels affected survival in our cohort.

Vitamin D deficiency is common in chronic liver diseases (CLDs), and vitamin D levels are negatively associated with liver function. ${ }^{[9,10]}$ In line with the above, we found that vitamin D levels were lower in cases of advanced cirrhosis per the CP score. Vitamin D deficiency has also been connected to hepatic dysfunction, and no difference in vitamin D levels has been detected according to CLD etiology. Vitamin D levels have been found to be significantly lower for higher CP grades, ${ }^{[6,11,12]}$ which also matches our study's findings. In addition, vitamin D levels have been recorded to decrease in HCC patients, and deficiency has been correlated with disease severity. ${ }^{[10]}$ Our study once again yielded results that are compatible with these data.

AFP levels play a key role in HCC diagnosis and follow-up, and they are important in early detection. They are also a predictor of survival. Levels above $400 \mathrm{ng} / \mathrm{dL}$ have been found to have a negative significant impact on survival in patients treated with TACE ${ }^{[13]}$ Moreover, an increase in AFP levels is a significant predictor of survival without a cutoff. ${ }^{[14]}$ We concordantly found that AFP levels above $400 \mathrm{ng} / \mathrm{dL}$ were a negative, statistically significant prognostic factor. BCLC grades have been widely used to define treatment options, and they correlate with the advance of the disease. Advanced stages relate to a more negative prognosis, a fact that our study also arrived at. ${ }^{[15]}$

In answer to our main hypothesis, we did not find an impact of vitamin D levels on HCC patients' overall survival. In contrast to our results, a previous prospective study has shown that vitamin $\mathrm{D}$ levels below 10 $\mathrm{ng} / \mathrm{mL}$ impact overall survival negatively in HCC patients when compared to levels between 10 and $20 \mathrm{ng} / \mathrm{mL}$ and over $20 \mathrm{ng} / \mathrm{mL} \cdot{ }^{[6]}$ Also, in line with our results, another prospective study has shown that total and free vitamin D levels had no impact on overall survival, as well as, higher serum bioavailable vitamin D levels had a positive impact to the overall survival. ${ }^{[16]}$ However, in our study, vitamin D levels below $10 \mathrm{ng} / \mathrm{mL}$ did not have a negative impact on overall survival when compared with levels above $10 \mathrm{ng} / \mathrm{mL}$. Our retrospective study design may account for this difference. We recorded vitamin D levels a month before patients' HCC diagnosis and at any point thereafter, and we had no data on vitamin D replacement status.

Our study's retrospective design was, in fact, its main limitation. Other limitations included the absence of data on vitamin D replacement status and repetitive data on vitamin D levels. A greater population size would have also yielded more reliable results.

\section{Conclusion}

In conclusion, our study suggests that HCC grade and AFP levels substantially affect HCC patients' overall survival, but there appears to be no connection between vitamin D levels and overall survival. Further studies involving a larger sample size and a prospective design should shed new light on this topic.

Table 2. Multivariate analysis of the affecting factors on survival in hepatocellular carcinoma patients

\begin{tabular}{|c|c|c|c|c|c|c|}
\hline & \multicolumn{3}{|c|}{ Univariate analysis } & \multicolumn{3}{|c|}{ Multivariate analysis } \\
\hline Age $\leq 65$ years & 1.636 & $0.808-3.314$ & 0.172 & & & \\
\hline BCLC Grade & 1.166 & $1.224-2.268$ & $0.001^{*}$ & 1.974 & $1.377-2.830$ & $<0.001^{*}$ \\
\hline Vitamin $\mathrm{D} \leq 9 \mathrm{ng} / \mathrm{ml}$ & 2.137 & $1.010-4.519$ & $0.047^{\star}$ & & & \\
\hline
\end{tabular}

AFP: Alpha-fetoprotein; BCLC: Barcelona Clinic Liver Cancer; $\mathrm{Cl}$ : Confidence interval; HR: Hazard ratio; *: $p<0.05$ aacepted as significant. 
Ethics Committee Approval: The study was approved by the local ethics committee (Approval Date: 15 July 2016, Approval Number: 09.2016.418).

Peer-review: Externally peer-reviewed.

Author Contributions: Concept - FG, AB; Design - FG, AB; Supervision FG; Materials - AB; Data Collection and/or Processing - AB, FG; Analysis and/ or Interpretation - AB, HTK, EA, FG, YOA; Literature Search - AB, HTK, FG; Writing - AB, HTK, FG; Critical Reviews - AB, HTK, EA, YOA, OO, FG.

Conflict of Interest: The authors have no conflict of interest to declare.

Financial Disclosure: The authors declared that this study has received no financial support.

\section{References}

1. Global Burden of Disease Liver Cancer Collaboration, Akinyemiju T, Abera S, Ahmed M, Alam N, Alemayohu MA, et al. The Burden of Primary Liver Cancer and Underlying Etiologies From 1990 to 2015 at the Global, Regional, and National Level: Results From the Global Burden of Disease Study 2015. JAMA Oncol 2017;3(12):1683-1691.

2. White DL, Thrift AP, Kanwal F, Davila J, El-Serag HB. Incidence of Hepatocellular Carcinoma in All 50 United States, From 2000 Through 2012. Gastroenterology 2017;152(4):812-820.e5.

3. European Association for the Study of the Liver. Electronic address: easloffice@easloffice.eu; European Association for the Study of the Liver. EASL Clinical Practice Guidelines: Management of hepatocellular carcinoma. J Hepatol 2018;69(1):182-236.

4. Kanwal F, Singal AG. Surveillance for Hepatocellular Carcinoma: Current Best Practice and Future Direction. Gastroenterology 2019;157(1):54-64.

5. Schütte K, Schulz C, Malfertheiner P. Nutrition and Hepatocellular Cancer. Gastrointest Tumors 2016;2(4):188-194.

6. Finkelmeier F, Kronenberger B, Köberle V, Bojunga J, Zeuzem S, Trojan J, et al. Severe 25-hydroxyvitamin D deficiency identifies a poor prognosis in patients with hepatocellular carcinoma - a prospective cohort study. Aliment
Pharmacol Ther 2014;39(10):1204-1212.

7. Pourgholami MH, Akhter J, Lu Y, Morris DL. In vitro and in vivo inhibition of liver cancer cells by 1,25-dihydroxyvitamin D3. Cancer Lett 2000;151(1):97-102.

8. Caputo A, Pourgholami MH, Akhter J, Morris DL. 1,25-Dihydroxyvitamin $\mathrm{D}(3)$ induced cell cycle arrest in the human primary liver cancer cell line HepG2. Hepatology research: the official journal of the Japan Society of Hepatology 2003;26(1):34-39.

9. Kitson MT, Roberts SK. D-livering the message: the importance of vitamin D status in chronic liver disease. J Hepatol 2012;57(4):897-909.

10. Wu DB, Wang ML, Chen EQ, Tang H. New insights into the role of vitamin D in hepatocellular carcinoma. Expert Rev Gastroenterol Hepatol 2018;12(3):287-294.

11. Malham M, Jørgensen SP, Ott P, Agnholt J, Vilstrup H, Borre M, et al. Vitamin $\mathrm{D}$ deficiency in cirrhosis relates to liver dysfunction rather than aetiology. World J Gastroenterol 2011;17(7):922-925.

12. Buonomo AR, Zappulo E, Scotto R, Pinchera B, Perruolo G, Formisano P, et al. Vitamin $D$ deficiency is a risk factor for infections in patients affected by HCV-related liver cirrhosis. Int J Infect Dis 2017;63:23-29.

13. Prajapati HJ, Kim HS. Treatment algorithm based on the multivariate survival analyses in patients with advanced hepatocellular carcinoma treated with trans-arterial chemoembolization. PLoS One 2017;12(2):e0170750.

14. Berhane S, Fox R, García-Fiñana M, Cucchetti A, Johnson P. Using prognostic and predictive clinical features to make personalised survival prediction in advanced hepatocellular carcinoma patients undergoing sorafenib treatment. Br J Cancer 2019;121(2):117-124.

15. Bibani N, Trad D, Sabbah M, Ouakaa A, Elloumi H, Gargouri D, et al. Prognostic factors of survival during hepatocellular carcinoma. La Tunisie medicale 2018;96(6):379-384.

16. Fang AP, Long JA, Zhang YJ, Liu ZY, Li QJ, Zhang DM, et al. Serum Bioavailable, Rather Than Total, 25-hydroxyvitamin D Levels Are Associated With Hepatocellular Carcinoma Survival. Hepatology 2020;72(1):169182. 